\title{
REVIEW
}

\section{The role and function of cadherins in the mammary gland}

\author{
Jennifer L Andrews, Alvin C Kim and Julie R Hens*
}

\begin{abstract}
Cadherins are transmembrane receptors that function through calcium-dependent homophilic and heterophilic interactions that provide cell-cell contact and communication in many different organ systems. In the mammary gland only a few of the cadherins that make up this large superfamily of proteins have been characterized. Frequently in metastatic breast cancer, the genes for cadherins are epigenetically silenced, mutated, or regulated differently. During epithelialmesenchymal transition, cadherins that are expressed normally in the epithelial cells are down-regulated, while cadherins expressed in the mesenchyme are up-regulated. This process is known as cadherin switching, and its regulation can sometimes facilitate the increased motility, invasiveness and proliferation that occurs in metastatic cancer cells. Depending on the context, however, cell motility, invasiveness, proliferation and expression of mesenchymal markers can be independently modulated from cadherin expression, leading to partial epithelial-mesenchymal transitions and even mesenchymal-epithelial transitions (METs). This review will summarize the current understanding of cadherins found in the mammary gland and what is known about their mechanism of regulation in the mammary gland during normal physiological conditions and in breast cancer.
\end{abstract}

Members of the cadherin superfamily provide cell-cell contact and communication in many different organ systems. Cadherins comprise a large superfamily consisting of six groups: classical, fat and daschous, flamingo, protocadherins, 7-pass transmembrane, and desmosomal cadherins. They operate as transmembrane receptors

*Correspondence: jhens@sbu.edu

St Bonaventure University, Biology Department, William Walsh Science Building, \#213, St Bonaventure, NY 14778, USA that mediate calcium-dependent homophilic and heterophilic interactions between cells. These interactions are crucial for enhancing the cell's ability to not only interact with neighboring cells, but also for cell signaling [1]. This review will provide an overview of all cadherins known to be expressed in the mammary gland with particular focus on the less reviewed cadherins and atypical cadherins. Information on the regulation and function of these cadherins in the mammary gland and during breast cancer will be included.

Cadherins have specific structural features that are used to classify them into type I, type II, and type III or atypical cadherins (Figure 1). Type I cadherins possess a unique histidine-alanine-valine (HAV) motif in their amino acid sequence before the first calcium binding site in the amino terminus of the protein that is suggested to function in cadherin-cadherin interactions and has a single tryptophan (W) before the first calcium binding site. Type II cadherins contain the HAV motif, but this has two tryptophan residues (WW) instead of the one tryptophan found in type I cadherins. Type III or atypical cadherins possess calcium binding sites, but do not typically have HAV or W residues in their amino acid sequence [2]. All three classifications of cadherin are expressed in the mammary gland (Table 1 ).

\section{Type I cadherins}

Type I cadherins, which include epithelial $(E)$, neural $(N)$, placental $(\mathrm{P})$, and retinal $(\mathrm{R})$ cadherins, are expressed in the mammary gland [3-6]. E-cadherin is expressed exclusively in all of the mammary epithelial cells, while Pcadherin is expressed in mammary epithelial cells of the alveoli and ducts, but also in the myoepithelial cells $[3,5,7]$. N-cadherin is expressed in mesenchymal cells of the mammary stroma. R-cadherin, which was first identified in the retina, is expressed in the mammary epithelial cells [8].

In normal mammary epithelial cells, E-cadherin provides a tight connection between epithelial cells and localizes and interacts with components of the adherens junction. At the adherens junction, the E-cadherin cytoplasmic tail provides binding sites for $\mathrm{p} 120, \gamma$-catenin and $\beta$-catenin, providing a connection between the actin 


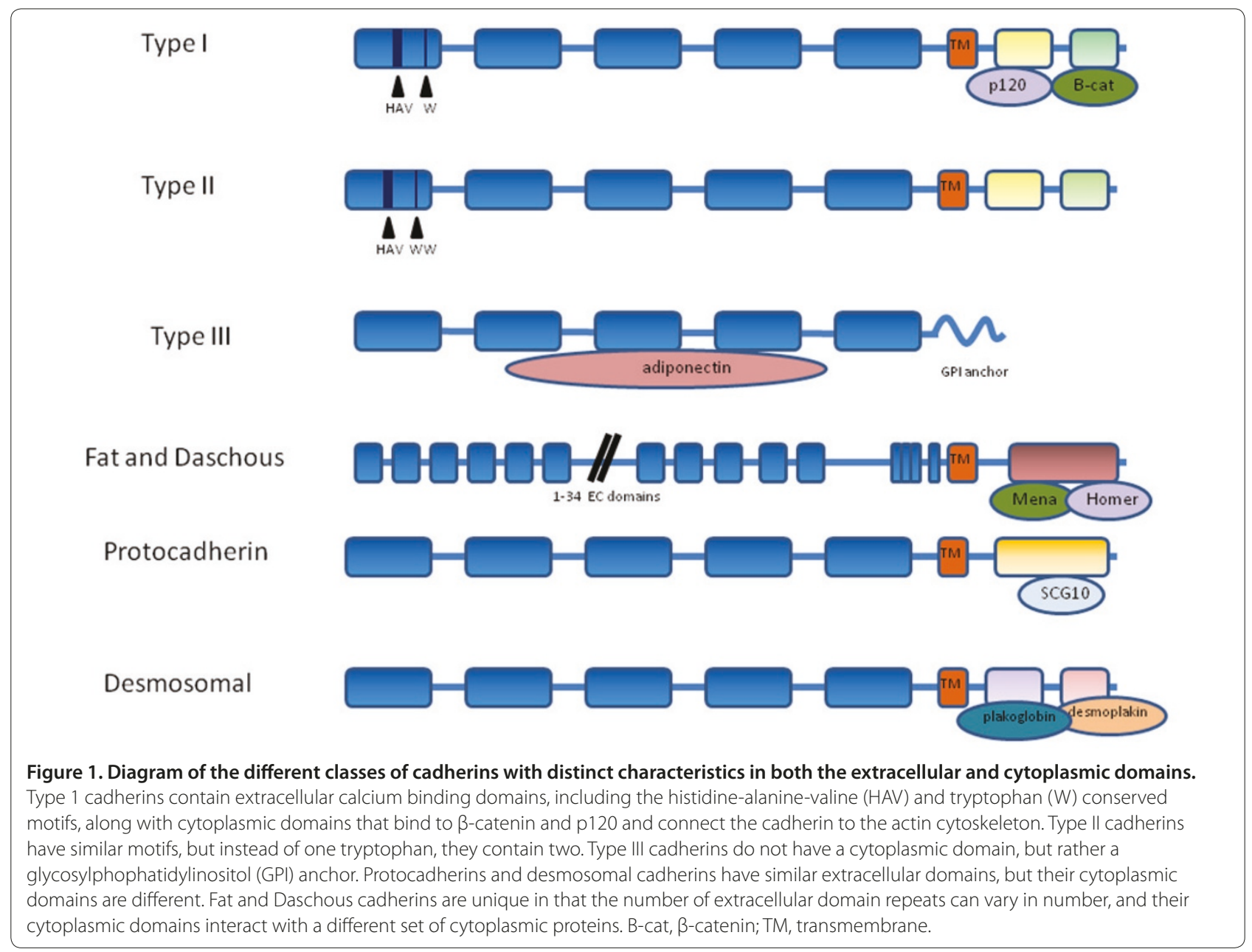

cytoskeleton and signaling pathways [2,9]. The relationship between E-cadherin and $\beta$-catenin is well studied and together these molecules stabilize the epithelial polarized cellular shape. E-cadherin joins with $\beta$-catenin to form an E-cadherin-catenin adhesion complex, which inhibits $\beta$-catenin's function in the canonical Wnt pathway. The sequestering of $\beta$-catenin by E-cadherin impairs the nuclear localization of $\beta$-catenin, which has been shown to induce a gene expression that guides a cell into favoring tumor invasion [10].

E-cadherin has been identified as a tumor suppressor gene and is modified in many cancers, including breast cancer. Because E-cadherin promotes adhesion and development of normal epithelial architecture and phenotype, its down-regulation in cancer cells is linked to an increase in epithelial-mesenchymal transition (EMT), motility, invasiveness, and overall metastasis $[11,12]$. Multiple transcriptional repressors, such as Zeb1, Zeb2, Snail1 and Snail2, are able to down-regulate E-cadherin, thus inhibiting the cell's ability to maintain proper adhesion properties and leaving the cell vulnerable to increased invasiveness and metastasis in breast cancer [13]. E-cadherin also interacts with epidermal growth factor (EGF) receptor to suppress receptor tyrosine kinase signaling, which regulates cell proliferation [14].

$\mathrm{N}$-cadherin is expressed normally in the mesenchymal cells of the mammary gland and interacts with the fibroblast growth factor (FGF) receptor (FGFR) pathway [15] and RhoGTPases [16,17]. The association of Ncadherin with FGFR prevents FGFR internalization and sustains FGF signaling. This lengthens the stimulation of the mitogen-activated protein kinase (MAPK)/ERK signaling pathway and induces the expression of matrix metalloprotease 9 , which increases cell motility [18]. In breast cancer cells, when $\mathrm{N}$-cadherin is misexpressed in the epithelial cells, it also increases cell motility through the RhoGTPases and provides the epithelial cells the ability to interact with stroma and endothelial cells through homophilic binding to N-cadherin in these two cellular regions, enabling the cancer cells to become metastatic and survive in other tissues [17]. Interestingly, not only does $\mathrm{N}$-cadherin function at the membrane, but 
Table 1. Identification and description of cadherins present in the mammary gland and altered in breast cancer

\begin{tabular}{lllll}
\hline Cadherin & Name & Classification & $\begin{array}{l}\text { Localization in the } \\
\text { mammary gland }\end{array}$ & Involvement in breast cancer \\
\hline CDH1 & E-cadherin & Classical type I & Luminal epithelial & Downregulated and overexpression, somatic mutations \\
$\mathrm{CDH} 2$ & N-cadherin & Classical type I & Nerve and mesenchymal & Upregulated \\
$\mathrm{CDH3}$ & P-cadherin & Classical type I & Myoepithelial, ducts and alveoli & Upregulated \\
$\mathrm{CDH} 4$ & R-cadherin & Classical type I & Epithelial & Downregulated \\
$\mathrm{CDH5}$ & VE-cadherin & Classical type II & Vascular endothelial & Overexpression and misexpressed \\
$\mathrm{CDH11}$ & OB-cadherin & Classical type II & Unknown & Upregulated in epithelial \\
$\mathrm{CDH13}$ & T/H-cadherin & Classical type III & Ductal epithelium, endothelial and & Downregulated/decreased expression, promoter \\
& & smooth muscle cells & methylation \\
CDH15 & M-cadherin & Classical type III & Unknown & Downregulated, LOH \\
FAT4 & Protocadherin Fat4 & Fat and Daschous & Epithelial & Downregulated, promoter methylation \\
PCDH8 & Protocadherin-8 & Protocadherin & Luminal epithelial & Downregulated, somatic missense, LOH, homozygous \\
& & & deletion, promoter methylation \\
PCDH10 & OL-protocadherin & Protocadherin & Epithelial & Downregulated, frequent promoter methylation \\
DSG2 & Desmoglein-2 & Desmosomal & Epithelial & Unknown \\
DSC3 & Desmocollin-3 & Desmosomal & Epithelial & Downregulated, promoter methylation
\end{tabular}

$\mathrm{LOH}$, loss of heterozygosity.

it also can transcriptionally regulate gene expression in the nucleus of neuronal cells. Presenilin-1 $\gamma$-secretase can cleave the cytoplasmic tail of $\mathrm{N}$-cadherin to release a $35 \mathrm{kDa}$ fragment that has the ability to translocate into the nucleus and bind to the transcriptional coactivator CREB binding protein (CBP) and target it for degradation, which represses CBP/CREB-mediated transcription $[19,20]$. It remains to be seen whether this processing of $\mathrm{N}$-cadherin occurs in mammary epithelial cells.

$\mathrm{P}$-cadherin is expressed in myoepithelial cells in the mammary gland [21]. Little is known about the normal function and regulation of P-cadherin in myoepithelial cells, but many breast cancer studies have examined the expression of P-cadherin. Aberrant expression of Pcadherin is seen in $30 \%$ of patients with breast carcinomas and is used as a marker for poor prognosis [22]. Usually the increased expression of P-cadherin is associated with a lack of estrogen receptor- $\alpha$ signaling and results in increased levels of c-erbB- 2 and p53 expression, which lead to increased cell proliferation [23,24]. Changes in estrogen signaling can cause chromatin remodeling at the $\mathrm{P}$-cadherin promoter, enabling $\mathrm{C} / \mathrm{EBP} \beta$ to increase P-cadherin expression. Several clinical studies are examining whether the inhibition of P-cadherin with monoclonal antibodies can reduce the metastatic potential of the cancer cells [25].

$\mathrm{R}$-cadherin, which was first identified in the retina, is expressed at similar levels to E-cadherin in the mammary gland. Localization studies showed that R-cadherin is expressed in the mammary epithelial cells that comprise the ducts and lobules [8]. The function of R-cadherin in the normal mammary gland is not known, but in breast cancer cells, R-cadherin expression is repressed and cells acquire a more metastatic phenotype. It has been shown that the loss of R-cadherin changes the epithelial phenotype, which suggests that R-cadherin is involved not only at the adherens junction but also to maintain the polarity of the cells $[8,26]$.

\section{Type II cadherins}

Presently only two type II cadherins have been identified as expressed in cells that comprise the mammary gland (Table 1). Cadherin-5, which is also called vascular endothelial cadherin, is found in endothelial cells and is part of the adherens junction that maintains blood vessel integrity. During invasive mammary carcinomas, cadherin-5 regulation is altered and it becomes expressed in the mammary epithelial cells and endothelial cells [27]. This enhances the ability of the mammary epithelial cells to adhere to endothelial cells, cross into the bloodstream and become metastatic. In a study with malignant fibroblastoid tumor cells that have increased cadherin-5 expression, mammary epithelial cells were stimulated to increase proliferation by increasing activation of SMAD-2, the transcription factor that is regulated by the transforming growth factor- $\beta$ signaling pathway [27]. This demonstrates that an increase in cadherin-5 expression during breast cancer can increase rates of proliferation of the carcinoma cells.

Cadherin-11, which was originally named ob-cadherin due to its discovery in osteoblasts, is considered a mesenchymal cadherin and is expressed in many types of condensing mesenchymes that form bone, somites and limbs [28-30]. The expression of cadherin-11 in 
osteoblasts and fibroblast-like synoviocytes helps maintain bone and joint structures [29-31]. Little is know about where cadherin-11 is expressed normally in the mammary gland, but in several breast cancer cell lines and during mammary carcinomas, cadherin- 11 becomes expressed in the epithelial cells, suggesting an EMT has occurred [32-34]. Once the carcinoma cells express cadherin-11, it provides the ability of metastatic carcinoma cells to establish themselves into the microenvironment of bone [34]. This is facilitated by the fact that both osteoblasts and the carcinoma cells express cadherin-11, enabling cell-cell interactions. In breast cancer cell lines, it was also demonstrated that if a truncated version of cadherin-11 derived from alternative splicing is co-expressed with the full length version of cadherin-11, there is an increase in invasive behavior of the breast cancer cells [33]. Transcriptional regulation of cadherin-11 has not been examined to any great extent in the literature, but at the translational level in breast cancer cells, cadherin-11 expression is down-regulated by $\beta$-catenin binding to the 3' untranslated region directed by glycogen synthase kinase- $\beta$ [35]. Additionally, interactions between cadherin-11 and fibroblast growth factor receptor 1 occur during the formation of neurite growth cones [36], which may suggest that cadherin-11 in the mammary gland interacts with the FGFRs located there.

\section{Type III/atypical cadherins}

Type III or atypical cadherins that have been demonstrated to be associated with the mammary gland are cadherin-13 and cadherin-15 (Table 1). Cadherin-13, which is also referred to as $\mathrm{T}$ - or $\mathrm{H}$-cadherin, is expressed in multiple cell types in the mammary gland, including myoepithelial, epithelial and endothelial cells [37]. It is a more unique cadherin since it does not have a transmembrane domain, but rather has a glycosylphosphatidylinositol anchor, and also because it localizes to the apical surface of polarized mammary epithelial cells rather than the basolateral surface [38]. Characterization of cadherin-13 suggests that it is not necessarily involved in adhesion but instead is an adiponectin receptor [39]. Adiponectin is secreted by adipocytes and can sequester growth factors. Since cadherin-13 is increased in endothelial cells during breast cancer, it would provide a more favorable environment rich in growth factors for the mammary tumor cells while attracting the tumor cells to the blood vessels. In mouse mammary tumor models, the expression of cadherin-13 is reduced in all cell types except endothelial cells. In cancer cell lines and primary breast cancers, cadherin-13 is repressed by methylation at the promoter. Further transcriptional repression of cadherin-13 can occur through Zeb-1 signaling, as is seen in gall bladder cancer, which results in a more invasive phenotype [40]. The repression of cadherin-13 increases the cancer cells' ability to invade, metastasize and form tumors $[37,41,42]$.

Cadherin-15 or muscle (M)-cadherin is expressed during myogenesis but has not been examined in normal mammary gland physiology. In mouse mammary tumor virus/neu transgenic mice the region on chromosome 8 where the M-cadherin gene is located is frequently lost in mouse mammary tumors and it is suggested that Mcadherin may also be a tumor suppressor gene [43].

\section{Protocadherins}

Protocadherins have been classified into two main families, clustered and not clustered, based on the location of the genes on the chromosome. More is known about the non-clustered protocadherins that consist of 11 known members, which has been further divided into three subfamilies in mammals: $\alpha-, \beta-$, and $\gamma$-protocadherins [44]. Protocadherin 4, which is also named FAT4, is epigenetically repressed in breast cancers by methylation at the promoter. In mice mammary tumor models, it was seen that if one copy of the Fat4 gene was deleted, it resulted in the methylation and repression of the other copy of Fat4 [45].

The expression and function of protocadherins in normal mammary physiology are unknown. In Drosophila, the protocadherin homologs Fat and Dachsous proteins act as a receptor-ligand pair involved in planar cell polarity events and function during growth, branching and cell survival of many organ systems. In the mouse, the Fat homolog called protocadherin-4 and Dachsous proteins are expressed in mesenchymal cells of many organs and act similarly to the homologs in Drosophila [46]. Both protocadherin-8 and protocadherin-10 are considered to be tumor suppressors and are mutated and repressed in many breast cancer cell lines [47]. The rat homolog of protocadherin- 8 is called Arcadlin, and it has been shown to interact with $\mathrm{N}$-cadherin and cadherin-11 at the hippocampal synapses to regulate endocytosis [48]. However, no other information is known about the function of protocadherins in normal mammary physiology, let alone in mammary carcinomas.

\section{Desmosomal cadherins}

Desmosomal cadherins belong to a family of proteins involved in the structure of the desmosome and hemidesmosomes, which enable cells to adhere to each other and to the stroma. During cancer, there is an increase in transmembrane metalloprotease activity, which results in ectoderm shedding of cell surface molecules, facilitating the ability of cells to become mobile and invasive. In some breast cancers, $A D A M 17$ is up-regulated by EGF and this causes increased ectoderm shedding of ADAM17 targets, such as desmoglein-2, a desmosomal 
cadherin [49]. Desmocollin-3, also a component of the desmosome in epithelial cells, was down-regulated by epigenetic silencing at the promoter by methylation in several breast cancer cell lines [50]. Because in cancer cells the desmosomal cadherins are down-regulated epigenetically at the promoter in addition to ectoderm shedding, they have also been identified as tumor suppressor genes.

\section{Role of cadherins in breast cancer}

The role cadherins play in breast cancer is of fundamental importance to understanding the disease and developing treatments. Three events that can strongly influence the expression of cadherins present in breast carcinomas include cadherin switching, EMT, and MET. Cadherin switching is where the type of cadherins change from those expressed in epithelial cells to those expressed more in mesenchymal cells [18]. It has been described as a normal mechanism occurring in mammary tubulogenesis and during wound healing, providing intermediate phenotypes with both epithelial and mesenchymal characteristics [51,52]. This event is followed by EMT, where the epithelial cells become more mobile and invasive, and increase their levels of proliferation. Cancer cells that have gone through EMT migrate to a secondary site in the body where they sometimes go through MET, reverting back to a more epithelial phenotype [53]. Further, these transitions are not always necessarily complete, in that partial EMT and MET are seen in some cancers [53-55]. These phenotypic transition events during cancer can result in a more malignant and metastatic cancer.

In some ways it should not be a surprise that EMT, MET, and intermediate cell phenotypes exist, since these are all dynamic processes that depend on the context of both the cell and the environment. Several different gene profiles for EMT have been identified in breast cancer tissue samples [54]. Most research has focused on Ecadherin expression and regulation during EMT. However, increasing evidence suggests that cancer cells can have low E-cadherin levels but are not migratory and that some breast cancer cells may not have all the mesenchymal markers (vimentin, fibronectin, N-cadherin) seen in an EMT. Part of the difficulties lies in the fact that there are multiple ways to regulate cadherins and the mesenchymal markers during the process and some, but not all, of the regulatory pathways overlap.

In a differentiated mammary epithelial cell, E-cadherin is present at the adherens junctions. Although initially Ecadherin was considered just a structural protein, it can act as a tumor suppressor and in many cancers it is silenced. Several microRNAs (miRNAs) that belong to the miRNA200 family have been demonstrated to enable differentiation of the mammary epithelial cells [56].
These miRNAs protect E-cadherin from down-regulation by targeting the E-box binding zinc finger transcription factors Zeb1 and Zeb2, which can suppress E-cadherin transcription $[13,40]$. E-cadherin also interacts with members of the FGF, EGF, and Wnt families. These interactions create a fine balance of signals through several intracellular pathways involving $\beta$-catenin, glycogen synthase kinase (GSK) $\beta$, and AKT (Figure 2a). Bcatenin is a multifunctional protein involved with canonical Wnt signaling by acting as a co-transcription factor, but it also interacts with the cytoplasmic tail of E-cadherin at adherens junctions, where it connects the adherens junction to the actin cytoskeleton. E-cadherin can suppress canonical Wnt signaling by sequestering the $\beta$-catenin to its cytoplasmic tail, which prevents $\beta$ catenin from entering the nucleus where it can act to change transcription of genes downstream of canonical Wnt signaling.

During breast cancer, changes in E-cadherin regulation result in down-regulation of E-cadherin (Figure 2b), which can, in some cases, facilitate an EMT. The loss or down-regulation of E-cadherin can occur through several different mechanisms. One of the most obvious changes that can occur is the accumulation of mutations in the genome at and near the cadherin genes, resulting in a loss of heterozygosity and inactivation of specific cadherins that can then lead to cancer [43]. Changes in transcriptional regulation of cadherins can occur on several levels. Epigenetic silencing can occur by either methylation at the promoter and by noncoding RNAs that can repress cadherin expression [1,12]. In some breast cancers, somatic E-cadherin loss of function mutations occur in a sporadic lobular subtype [20,57]. Additionally, hypermethylation at $\mathrm{CpG}$ islands on the $\mathrm{CDH} 1$ gene promoter has been documented in several cancers and mammary carcinomas [58-60].

Silencing of the $C D H 1$ gene can also occur through transcriptional modulators. During EMT, the Snail family of suppressor transcription factors (Snail1 and Slug) and E-box-binding zinc finger transcription factors Zeb1 and Zeb2 coordinate the reduction of E-cadherin expression while increasing $\mathrm{N}$-cadherin levels, which contribute to the EMT. The coordination of this regulation is through Snail, which turns on Zeb1 transcription and directs Zeb1 to bind to the E-box motif on the E-cadherin promoter, which blocks transcription of the gene $[13,40]$ (Figure 2b). These transcriptional suppressors include the basic helix-loop-helix (bHLH) family members Twist and E12/47 (the $e 2 A$ gene product), the Snail family, Snail1 and Snail2 (Slug), and members of the zinc finger homeobox family of repressors, including ZEB1 (TCF8 or $\delta E F 1$ ) and ZEB2 (ZFXH1B or SIP1). It is these transcription factor modulators that provide much of the confusion when characterizing breast cancer cells going through 
(a)

\section{Epithelial Cell}

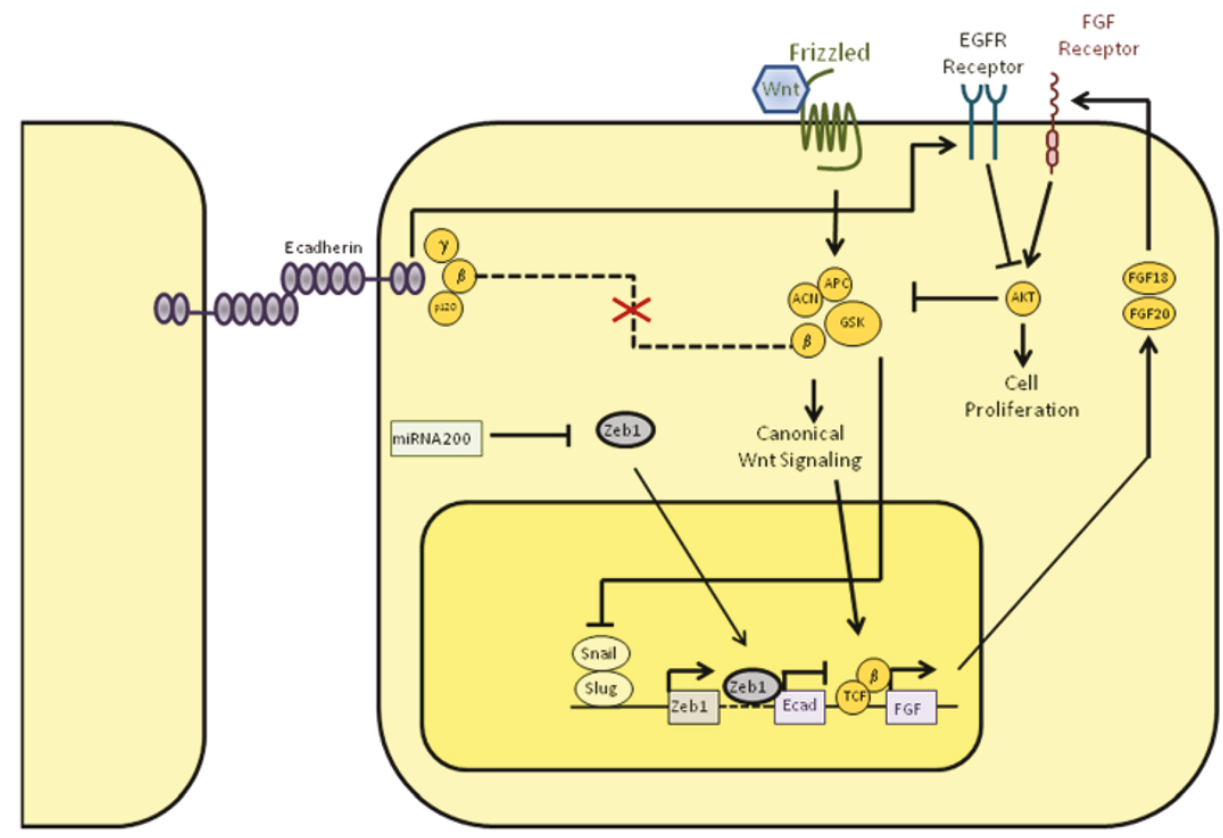

(b) EMTEpithelial Cell

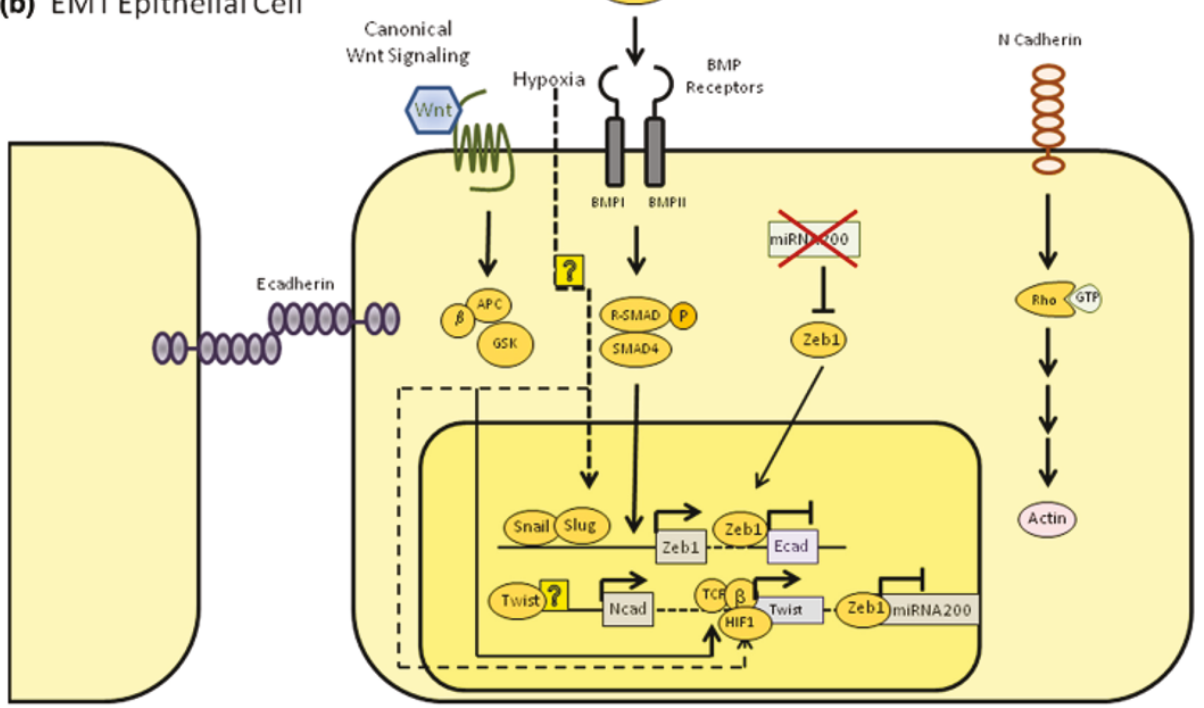

Figure 2. A mammary epithelial cell showing changes in the signaling pathways that are altered when an epithelial cell goes through epithelial-mesenchymal transition. (a) Normal mammary epithelial cell showing the signaling pathways and transcription factors that affect the epithelial phenotype. (b) A mammary epithelial cell going through epithelial-mesenchymal transition (EMT) showing the signaling pathways that facilitate the mesenchymal phenotype. BMP, bone morphogenetic protein; cad, cadherin; EGFR, epidermal growth factor receptor; FGF, fibroblast growth factor; GSK, glycogen synthase kinase; miRNA, microRNA; TCF, T-cell factor; TGF transforming growth factor.

EMT, MET or partial reversions. This is due to the fact that some of these transcription factors regulate not only E-cadherin but also some of the mesenchymal markers $[61,62]$.

Both Snail and Slug can repress E-cadherin expression in several breast cancer cell lines, and it has been suggested that Slug is highly correlated to down-regulation of E-cadherin in breast carcinomas in vivo [63,64]. Both of these repressors have been demonstrated to down-regulate E-cadherin [65]. GSK $\beta$ was demonstrated to inhibit Snail and Slug's ability to activate Zeb. Snail was not demonstrated to be correlated with breast ductal 
tumor progression in one study, but has been demonstrated to down-regulate estrogen synthesase [66] and Lundgren and colleagues [55] identified impaired tamoxifen response in tumors with reduced Snail expression. These findings would then alter strategies for breast cancer therapies that involve aromatase suppressors [67]. Overall, it is clear that Snail and Slug indirectly regulate E-cadherin through regulation of Zeb1 and Zeb2. Zeb1 can bind to the E-cadherin promoter and down-regulate E-cadherin expression, and Zeb1 can down-regulate miRNAs that induce a more epithelial phenotype in the cell, indirectly reducing E-cadherin expression. Further studies need to examine Snail and Slug downstream targets and whether they are targeting the mesenchymal markers.

The transcription factor ZEB1 can regulate cell fate determination and development of mesodermally derived tissue. It binds to DNA through the E-box consensus motif and acts as a transcriptional activator, interacting with acetyltransferase p300/pCAF and activated SMADs [68-70]. Mutations in the ZEB1 gene can cause METs with increased ectopic expression of E-cadherin [71]. Transforming growth factor- $\beta$, tumor necrosis factor- $\alpha$, and insulin-like growth factor-1 signaling can activate ZEB1 expression and induce EMT in cancer while decreasing E-cadherin expression [69,72]. ZEB1 can interact independently with both the co-repressor CTBP and SWI/ SNF chromatin-remodeling protein BRG1 and downregulate E-cadherin expression [73]. ZEB1 and BRG1 have been colocalized in the nucleus in dedifferentiated epithelial cells found at the edge of tumors together with nuclear $\beta$-catenin. Besides decreasing E-cadherin expression, ZEB1 can also down-regulate several miRNAs that increase epithelial-like phenotypes $[13,56,74,75]$. Thus, the changes in regulation of E-cadherin expression are not dependent on the mesenchymal proteins being upregulated. The down-regulation of E-cadherin and the up-regulation of mesenchymal markers appear to be two separate events, although the transcriptional suppressors are shared between the two events.

Twist is a bHLH protein involved in the differentiation of several cellular lineages, including myogenesis, osteogenesis, and neurogenesis [76-79]. Twist can activate EMT by down-regulation of E-cadherin and increasing $\mathrm{N}$-cadherin expression in the fruit fly [80]. In one study on breast carcinomas, it was demonstrated that upregulation of Twist was associated with resistance to paclitaxel and led to resistance to microtubule-disrupting anticancer drugs $[81,82]$. In mouse models, up-regulation of Twist was associated with a decrease in E-cadherin, activation of mesenchymal markers, and increased metastasis [83]. In the mouse mammary tumor model, Wnt 1 signaling through $\beta$-catenin regulated Twist expression, and both can suppress mammary differentiation, which will permit further cell growth and tumorigenesis to continue [84] (Figure 2b). Therefore, in breast cancers where Twist is over-expressed, both increases in mesenchymal markers and also decreases in E-cadherin can occur.

Additionally, the environment where the breast cancer cells reside can modulate the mechanisms involved in EMT or MET [55]. Both secondary sites of cancer and hypoxia can alter the expression of cadherins and mesenchymal proteins $[53,55,85]$. Recently, Chao and colleagues [53] demonstrated that MET can occur by reexpression of E-cadherin in metastatic breast cancers at the secondary sites populated by the cancer cells. The reexpression of the E-cadherin gene was dependent on the inability of a DMA methyltransferase to methylate the DNA after DNA replication at the secondary site; this occurred at the edge of tumors and was suggested to need cell contacts with the secondary organ's cells. A second mechanism for altering gene profiles of breast carcinomas deals with the hypoxic conditions that arise in the middle of tumors. Specifically, hypoxia can independently affect transcriptional regulators such as SNAIL without initiating mechanisms involved in cell motility and migration and nor through the regulation of hypoxia-inducible factor (HIF)-1-activated genes involved in proliferation and EMT $[55,85,86]$. SNAIL expression was stimulated in cells exposed to high levels of hypoxia and resulted in SNAIL localizing to the nucleus, where it can be stabilized by a small carboxyterminal domain phosphatase (SCP) [87]. SNAIL can then bind to the ZEB1 promoter and lead to ZEB1 inhibition of the E-cadherin gene. Phosphorylation of SNAIL by GSK $\beta$ revealed a nuclear localization signal that enabled SNAIL to exit the nucleus $[88,89]$. This would enable the re-expression of $C D H 1$ and other genes repressed by SNAIL. SNAIL does not directly alter the expression of mesenchymal proteins like vimentin and Ncadherin; instead, TWIST can be activated through HIF1 to increase vimentin and $\mathrm{N}$-cadherin expression [85]. Therefore, in a hypoxic environment both SNAIL and TWIST are regulated separately and independently to assist cells in surviving the tumor environment.

Other signaling pathways, including canonical Wnt, EGF and FGF signaling, are involved in the proliferation and altered regulation occurring in mammary carcinoma cells and have been shown to interact with different cadherins. What is known is that several of the cadherins can interact with these pathways to increase cell proliferation and alter the actin cytoskeleton [14]. E-cadherin interacts with the EGF receptor, and sustains growth and proliferation signals by possibly preventing endocytosis, which would prevent the EGF receptor from being recycled [14]. Canonical Wnt signaling has been implicated in breast cancer, ever since the mouse mammary 
tumor virus model (Wnt-1) was developed. The EGF signaling pathway was shown to interact with the Wnt signaling pathways. This interaction disrupts GSK $\beta$ function and enables an increase in $\beta$-catenin expression in the cytoplasm, which leads to an increase of $\beta$-catenin in the nucleus, where it can act as a co-transcription factor with T-cell factor (TCF) transcription factors. Cadherins can also provide the ability to modulate the Wht signaling pathway by altering localization of $\beta$ catenin in the cell $[26,35]$. E-cadherin binds to $\beta$-catenin in its cytoplasmic tail and it is now clear that E-cadherin can inhibit the Wnt signaling response by binding to $\beta$ catenin and preventing it from entering the nucleus. Canonical Wnt signaling can regulate Twist through a $\beta$ catenin-TCF complex interacting at the Twist promoter, which can increase the expression of N-cadherin. Ncadherin and cadherin-11 both have recently been identified to interact with the FGF signaling pathway by binding to FGFRs and sustaining the FGF signal by preventing the internalization of the FGFR $[15,36]$. Therefore, cadherins can modulate the response to growth factors by inhibiting receptor internalization in addition to sequestering the cytoplasmic factors, such as $\beta$-catenin, needed for transcriptional regulation of the genes downstream of the growth factors.

\section{Conclusion}

Regulatory mechanisms that alter transcriptional, translational, and post-translational regulation of cadherins have provided cancer cells with the means to proliferate and survive in many different tissue environments. Many questions still need to be answered about the function and regulation of many cadherins in the mammary gland, both during normal and cancerous physiology. The recent controversy about EMT and partial EMT and MET can be cleared up by understanding the differences in the function and roles of the various repressors, activators and growth factors in mammary epithelial cells. Although EMT is described as a multi-step process that begins with the down-regulation of E-cadherin, it needs to be recognized that the regulation of E-cadherin is separate from that of mesenchymal proteins. In addition, the environment where the cancer cells are found can also influence the regulation of the cadherins.

Future research should examine how the environment affects cancer cells' expression of different cadherins. When gene expression profiles for various cancers are created, it is important to recognize the environment and location these samples are taken from as different locations can alter gene expression profiles. Profiles of gene expression within a tumor mass will be different from those of tumor cells at the edge of the organs. The mechanisms for regulating cadherin through noncoding RNAs and suppressor transcription factors have been identified for E-cadherin, but still need to be examined for other cadherins to determine whether these mechanisms will become a paradigm. Further studies examining cadherin regulation by transcriptional activators and suppressors and miRNAs on other cadherins is still needed. The roles of the many other cadherins, such as protocadherins and atypical cadherins, still need to be examined in the mammary gland; knowing these will help researchers understand the connections between different cell types in this organ. Understanding how these proteins are mutated and how these mutations affect their regulation will be crucial for identifying new therapies and treatments for breast cancer.

\section{Abbreviations}

bHLH, basic helix-loop-helix; E, epithelial; EGF, epidermal growth factor; EMT, epithelial-mesenchymal transition; FGF, fibroblast growth factor; FGFR, fibroblast growth factor receptor; GSK, glycogen synthase kinase; $H A V$, histidine-alanine-valine; HIF, hypoxia-inducible factor; $M$, muscle; MET, mesenchymal-epithelial transition; miRNA, microRNA; N, neural; P, placental; $R$, retinal; TCF, T-cell factor.

\section{Competing interests}

The authors declare that they have no competing interests.

\section{Published: 8 February 2012}

\section{References}

1. Peinado $H$, Portillo F, Cano A: Transcriptional regulation of cadherins during development and carcinogenesis. Int J Dev Bio/ 2004, 48:365-375.

2. Nelson WJ: Regulation of cell-cell adhesion by the cadherin-catenin complex. Biochem Soc Trans 2008, 36:149-155.

3. Hazan RB, Kang L, Whooley BP, Borgen PI: N-cadherin promotes adhesion between invasive breast cancer cells and the stroma. Cell Adhes Commun 1997, 4:399-411.

4. Radice GL, Sauer CL, Kostetskii I, Peralta Soler A, Knudsen KA: Inappropriate $\mathrm{P}$-cadherin expression in the mouse mammary epithelium is compatible with normal mammary gland function. Differentiation 2003, 71:361-373.

5. Paredes J, Milanezi F, Reis-Filho JS, Leitao D, Athanazio D, Schmitt F: Aberrant P-cadherin expression: is it associated with estrogen-independent growth in breast cancer? Pathol Res Pract 2002, 198:795-801.

6. Sommers $\mathrm{CL}$ : The role of cadherin-mediated adhesion in breast cancer. J Mammary Gland Biol Neoplasia 1996, 1:219-229.

7. Paredes J, Milanezi F, Viegas L, Amendoeira I, Schmitt F: P-cadherin expression is associated with high-grade ductal carcinoma in situ of the breast. Virchows Arch 2002, 440:16-21.

8. Agiostratidou G, Li M, Suyama K, Badano I, Keren R, Chung S, Anzovino A, Hulit J, Qian B, Bouzahzah B, Eugenin E, Loudig O, Phillips GR, Locker J, Hazan RB: Loss of retinal cadherin facilitates mammary tumor progression and metastasis. Cancer Res 2009, 69:5030-5038.

9. Nelson WJ, Nusse R: Convergence of Wnt, beta-catenin, and cadherin pathways. Science 2004, 303:1483-1487.

10. Wheelock MJ, Johnson KR: Cadherin-mediated cellular signaling. Curr Opin Cell Biol 2003, 15:509-514.

11. Bracke ME, Depypere H, Labit C, Van MarckV, Vennekens K, Vermeulen SJ, Maelfait I, Philippe J, Serreyn R, Mareel MM: Functional downregulation of the E-cadherin/catenin complex leads to loss of contact inhibition of motility and of mitochondrial activity, but not of growth in confluent epithelial cell cultures. Eur J Cell Biol 1997, 74:342-349.

12. Tryndyak VP, Beland FA, Pogribny IP: E-cadherin transcriptional downregulation by epigenetic and microRNA-200 family alterations is related to mesenchymal and drug-resistant phenotypes in human breast cancer cells. Int J Cancer 2010, 126:2575-2583.

13. Schmalhofer O, Brabletz S, Brabletz T: E-cadherin, beta-catenin, and ZEB1 in malignant progression of cancer. Cancer Metastasis Rev 2009, 28:151-166.

14. Fedor-Chaiken M, Hein PW, Stewart JC, Brackenbury R, Kinch MS: E-cadherin binding modulates EGF receptor activation. Cell Commun Adhes 2003, 
10:105-118.

15. Suyama K, Shapiro I, Guttman M, Hazan RB: A signaling pathway leading to metastasis is controlled by $\mathrm{N}$-cadherin and the FGF receptor. Cancer Cell 2002, 2:301-314

16. Fukata M, Kaibuchi K: Rho-family GTPases in cadherin-mediated cell-cell adhesion. Nat Rev Mol Cell Biol 2001, 2:887-897.

17. Derycke LD, Bracke ME: N-cadherin in the spotlight of cell-cell adhesion, differentiation, embryogenesis, invasion and signalling. Int J Dev Bio/ 2004 48:463-476.

18. Cavallaro U, Schaffhauser B, Christofori G: Cadherins and the tumour progression: is it all in a switch? Cancer Lett 2002, 176:123-128.

19. Franberg J, Svensson Al, Winblad B, Karlstrom H, Frykman S: Minor contribution of presenilin 2 for gamma-secretase activity in mouse embryonic fibroblasts and adult mouse brain. Biochem Biophys Res Commun 2011, 404:564-568.

20. Berx G, van Roy F: Involvement of members of the cadherin superfamily in cancer. Cold Spring Harb Perspect Biol 2009, 1:a003129.

21. Daniel CW, Strickland P, Friedmann Y: Expression and functional role of $\mathrm{E}$ - and P-cadherins in mouse mammary ductal morphogenesis and growth. Dev Biol 1995, 169:511-519.

22. Turashvili G, McKinney SE, Goktepe O, Leung SC, Huntsman DG, Gelmon KA, Los G, Rejto PA, Aparicio SA: P-cadherin expression as a prognostic biomarker in a 3992 case tissue microarray series of breast cancer. Mod Pathol 2011, 24:64-81.

23. Paredes J, Albergaria A, Oliveira JT, Jeronimo C, Milanezi F, Schmitt FC: $\mathrm{P}$-cadherin overexpression is an indicator of clinical outcome in invasive breast carcinomas and is associated with $\mathrm{CDH} 3$ promoter hypomethylation. Clin Cancer Res 2005, 11:5869-5877.

24. Paredes J, Correia AL, Ribeiro AS, Albergaria A, Milanezi F, Schmitt FC: Pcadherin expression in breast cancer: a review. Breast Cancer Res 2007, 9:214.

25. Zhang CC, Yan Z, Zhang Q, Kuszpit K, Zasadny K, Qiu M, Painter CL, Wong A, Kraynov E, Arango ME, Mehta PP, Popoff I, Casperson GF, Los G, Bender S, Anderes K, Christensen JG, VanArsdale T: PF-03732010: a fully human monoclonal antibody against $\mathrm{P}$-cadherin with antitumor and antimetastatic activity. Clin Cancer Res, 16:5177-5188.

26. Zou W, Hu CH, Zhou JP: [Relationship between the expression of Ecadherin-catenins and alpha-, beta-, gamma-catenin and the metastasis and prognosis of breast cancer]. Hunan Yi Ke Da Xue Xue Bao 2002, 27:499-502.

27. Labelle M, Schnittler HJ, Aust DE, Friedrich K, Baretton G, Vestweber D, Breie $\mathrm{G}$ : Vascular endothelial cadherin promotes breast cancer progression via transforming growth factor beta signaling. Cancer Res 2008, 68:1388-1397.

28. Okazaki M, Takeshita S, Kawai S, Kikuno R, Tsujimura A, Kudo A, Amann E: Molecular cloning and characterization of OB-cadherin, a new member of cadherin family expressed in osteoblasts. J Biol Chem 1994, 269:12092-12098

29. Valencia X, Higgins JM, Kiener HP, Lee DM, Podrebarac TA, Dascher CC, Watts GF, Mizoguchi E, Simmons B, Patel DD, Bhan AK, Brenner MB: Cadherin-11 provides specific cellular adhesion between fibroblast-like synoviocytes. J Exp Med 2004, 200:1673-1679.

30. Kiener HP, Niederreiter B, Lee DM, Jimenez-Boj E, Smolen JS, Brenner MB: Cadherin 11 promotes invasive behavior of fibroblast-like synoviocytes. Arthritis Rheum 2009, 60:1305-1310.

31. Lee DM, Kiener HP, Agarwal SK, Noss EH, Watts GF, Chisaka O, Takeichi M, Brenner MB: Cadherin-11 in synovial lining formation and pathology in arthritis. Science 2007, 315:1006-1010.

32. Pishvaian MJ, Feltes CM, Thompson P, Bussemakers MJ, Schalken JA, Byers SW: Cadherin-11 is expressed in invasive breast cancer cell lines. Cancer Res 1999, 59:947-952.

33. Feltes CM, Kudo A, Blaschuk O, Byers SW: An alternatively spliced cadherin-11 enhances human breast cancer cell invasion. Cancer Res 2002, 62:6688-6697

34. Tamura D, Hiraga T, Myoui A, Yoshikawa H, Yoneda T: Cadherin-11-mediated interactions with bone marrow stromal/osteoblastic cells support selective colonization of breast cancer cells in bone. Int J Oncol 2008, 33:17-24.

35. Farina AK, Bong YS, Feltes CM, Byers SW: Post-transcriptional regulation of cadherin-11 expression by GSK-3 and beta-catenin in prostate and breast cancer cells. PLoS One 2009, 4:e4797.

36. Boscher C, Mege RM: Cadherin-11 interacts with the FGF receptor and induces neurite outgrowth through associated downstream signalling. Cell Signal 2008, 20:1061-1072

37. Hebbard LW, Garlatti M, Young LJ, Cardiff RD, Oshima RG, Ranscht B: T-cadherin supports angiogenesis and adiponectin association with the vasculature in a mouse mammary tumor model. Cancer Res 2008, 68:1407-1416.

38. Ranscht B, Dours-Zimmermann MT: T-cadherin, a novel cadherin cell adhesion molecule in the nervous system lacks the conserved cytoplasmic region. Neuron 1991, 7:391-402.

39. Takeuchi T, Misaki A, Chen BK, Ohtsuki Y: H-cadherin expression in breast cancer. Histopathology 1999, 35:87-88.

40. Adachi Y, Takeuchi T, Nagayama T, Ohtsuki Y, Furihata M: Zeb1-mediated T-cadherin repression increases the invasive potential of gallbladder cancer. FEBS Lett 2009, 583:430-436.

41. Lee SW: H-cadherin, a novel cadherin with growth inhibitory functions and diminished expression in human breast cancer. Nat Med 1996, 2:776-782

42. Toyooka KO, Toyooka S, Virmani AK, Sathyanarayana UG, Euhus DM, Gilcrease M, Minna JD, Gazdar AF: Loss of expression and aberrant methylation of the $\mathrm{CDH} 13$ (H-cadherin) gene in breast and lung carcinomas. Cancer Res 2001, 61:4556-4560.

43. Cool M, Jolicoeur P: Elevated frequency of loss of heterozygosity in mammary tumors arising in mouse mammary tumor virus/neu transgenic mice. Cancer Res 1999, 59:2438-2444.

44. Hulpiau P, van Roy F: New insights into the evolution of metazoan cadherins. Mol Biol Evol, 28:647-657.

45. Qi C, Zhu YT, Hu L, Zhu YJ: Identification of Fat4 as a candidate tumor suppressor gene in breast cancers. Int J Cancer 2009, 124:793-798.

46. Mao Y, Mulvaney J, Zakaria S, Yu T, Morgan KM, Allen S, Basson MA, FrancisWest $P$, Irvine KD: Characterization of a Dchs1 mutant mouse reveals requirements for Dchs1-Fat4 signaling during mammalian development. Development 2011, 138:947-957.

47. Yu JS, Koujak S, Nagase S, Li CM, Su T, Wang X, Keniry M, Memeo L, Rojtman A, Mansukhani M, Hibshoosh H, Tycko B, Parsons R: PCDH8, the human homolog of PAPC, is a candidate tumor suppressor of breast cancer. Oncogene 2008, 27:4657-4665.

48. Yasuda S, Tanaka H, Sugiura H, Okamura K, Sakaguchi T, Tran U, Takemiya T, Mizoguchi A, Yagita Y, Sakurai T, De Robertis EM, Yamagata K: Activityinduced protocadherin arcadlin regulates dendritic spine number by triggering $\mathrm{N}$-cadherin endocytosis via TAO2beta and p38 MAP kinases. Neuron 2007, 56:456-471.

49. Santiago-Josefat B, Esselens C, Bech-Serra JJ, Arribas J: Post-transcriptional up-regulation of ADAM17 upon epidermal growth factor receptor activation and in breast tumors. J Biol Chem 2007, 282:8325-8331.

50. Klus GT, Rokaeus N, Bittner ML, Chen Y, Korz DM, Sukumar S, Schick A, Szallasi $Z$ : Down-regulation of the desmosomal cadherin desmocollin 3 in human breast cancer. Int J Oncol 2001, 19:169-174.

51. Thiery JP: Epithelial-mesenchymal transitions in development and pathologies. Curr Opin Cell Biol 2003, 15:740-746.

52. Christiansen JJ, Rajasekaran AK: Reassessing epithelial to mesenchymal transition as a prerequisite for carcinoma invasion and metastasis. Cancer Res 2006, 66:8319-8326.

53. Chao YL, Shepard CR, Wells A: Breast carcinoma cells re-express E-cadherin during mesenchymal to epithelial reverting transition. Mol Cancer 2010, 9:179.

54. Dubois-Marshall S, Thomas JS, Faratian D, Harrison DJ, Katz E: Two possible mechanisms of epithelial to mesenchymal transition in invasive ductal breast cancer. Clin Exp Metastasis 2011, 28:811-818.

55. Lundgren K, Nordenskjold B, Landberg G: Hypoxia, Snail and incomplete epithelial-mesenchymal transition in breast cancer. Br J Cancer 2009, 101:1769-1781.

56. Park SM, Gaur AB, Lengyel E, Peter ME: The miR-200 family determines the epithelial phenotype of cancer cells by targeting the E-cadherin repressors ZEB1 and ZEB2. Genes Dev 2008, 22:894-907.

57. Berx G, Cleton-Jansen AM, Strumane K, de Leeuw WJ, Nollet F, van Roy F, Cornelisse $\mathrm{C}$ : E-cadherin is inactivated in a majority of invasive human lobular breast cancers by truncation mutations throughout its extracellular domain. Oncogene 1996, 13:1919-1925.

58. Graff JR, Gabrielson E, Fujii H, Baylin SB, Herman JG: Methylation patterns of the E-cadherin $5^{\prime} \mathrm{CpG}$ island are unstable and reflect the dynamic, heterogeneous loss of E-cadherin expression during metastatic 
progression. J Biol Chem 2000, 275:2727-2732.

59. Lynch HT, Grady W, Lynch JF, Tsuchiya KD, Wiesner G, Markowitz SD: E-cadherin mutation-based genetic counseling and hereditary diffuse gastric carcinoma. Cancer Genet Cytogenet 2000, 122:1-6.

60. Nass SJ, Herman JG, Gabrielson E, Iversen PW, Parl FF, Davidson NE, Graff JR: Aberrant methylation of the estrogen receptor and E-cadherin $5^{\prime} \mathrm{CpG}$ islands increases with malignant progression in human breast cancer. Cancer Res 2000, 60:4346-4348.

61. Vuoriluoto K, Haugen H, Kiviluoto S, Mpindi JP, Nevo J, Gjerdrum C, Tiron C, Lorens JB, Ivaska J: Vimentin regulates EMT induction by Slug and oncogenic $\mathrm{H}$-Ras and migration by governing Axl expression in breast cancer. Oncogene, 30:1436-1448.

62. Gemmill RM, Roche J, Potiron VA, Nasarre P, Mitas M, Coldren CD, Helfrich BA Garrett-Mayer E, Bunn PA, Drabkin HA: ZEB1-responsive genes in non-small cell lung cancer. Cancer Lett 2011, 300:66-78.

63. Hajra KM, Chen DY, Fearon ER: The SLUG zinc-finger protein represses E-cadherin in breast cancer. Cancer Res 2002, 62:1613-1618.

64. Hajra KM, Fearon ER: Cadherin and catenin alterations in human cancer. Genes Chromosomes Cancer 2002, 34:255-268.

65. Bolos V, Peinado H, Perez-Moreno MA, Fraga MF, Esteller M, Cano A: The transcription factor Slug represses E-cadherin expression and induces epithelial to mesenchymal transitions: a comparison with Snail and E47 repressors. J Cell Sci 2003, 116:499-511.

66. Martin TA, Watkins G, Lane J, Jiang WG: Assessing microvessels and angiogenesis in human breast cancer, using VE-cadherin. Histopathology 2005, 46:422-430.

67. Chen X, Ding J, Gao W, Yi X, Wang H, Li H: [Expression of E-cadherin in nonsmall cell lung cancer: correlation with lymphatic metastasis and prognosis.] Zhongguo Fei Ai Za Zhi 2002, 5:260-262.

68. Nishimura Y, Yoshioka K, Bernard O, Bereczky B, Itoh K: A role of LIM kinase 1/ cofilin pathway in regulating endocytic trafficking of EGF receptor in human breast cancer cells. Histochem Cell Biol 2006, 126:627-638.

69. Postigo AA, Depp JL, Taylor JJ, Kroll KL: Regulation of Smad signaling through a differential recruitment of coactivators and corepressors by ZEB proteins. EMBO J 2003, 22:2453-2462.

70. Postigo AA: Opposing functions of ZEB proteins in the regulation of the TGFbeta/BMP signaling pathway. EMBO J 2003, 22:2443-2452.

71. Liu T, Dong $X G$, Wang $Y$, Yan $Y$, Zhang JJ: [The mechanism of twist gene regulation during the retina angiogenesis.] Zhonghua Yan Ke Za Zhi 2008, 44:634-639.

72. Graham TR, Zhau HE, Odero-Marah VA, Osunkoya AO, Kimbro KS, Tighiouart M, Liu T, Simons JW, O'Regan RM: Insulin-like growth factor-I-dependent up-regulation of ZEB1 drives epithelial-to-mesenchymal transition in human prostate cancer cells. Cancer Res 2008, 68:2479-2488.

73. Sanchez-Tillo E, Lazaro A, Torrent R, Cuatrecasas M, Vaquero EC, Castells A, Engel $P$, Postigo A: ZEB1 represses E-cadherin and induces an EMT by recruiting the SWI/SNF chromatin-remodeling protein BRG1. Oncogene 2010, 29:3490-3500

74. Burke JM: Epithelial phenotype and the RPE: is the answer blowing in the Wnt? Prog Retin Eye Res 2008, 27:579-595

75. Wang F, Sloss C, Zhang X, Lee SW, Cusack JC: Membrane-bound heparin-binding epidermal growth factor like growth factor regulates E-cadherin expression in pancreatic carcinoma cells. Cancer Res 2007, 67:8486-8493.

76. Jiang WG: E-cadherin and its associated protein catenins, cancer invasion and metastasis. Br J Surg 1996, 83:437-446.

77. Hamamori Y, Wu HY, Sartorelli V, Kedes L: The basic domain of myogenic basic helix-loop-helix (bHLH) proteins is the novel target for direct inhibition by another bHLH protein, Twist. Mol Cell Biol 1997, 17:6563-6573.

78. Maestro R, Dei Tos AP, Hamamori Y, Krasnokutsky S, Sartorelli V, Kedes L, Doglioni C, Beach DH, Hannon GJ: Twist is a potential oncogene that inhibits apoptosis. Genes Dev 1999, 13:2207-2217.

79. Castanon I, Von Stetina S, Kass J, Baylies MK: Dimerization partners determine the activity of the Twist bHLH protein during Drosophila mesoderm development. Development 2001, 128:3145-3159.

80. Oda H, Tsukita S, Takeichi M: Dynamic behavior of the cadherin-based cellcell adhesion system during Drosophila gastrulation. Dev Biol 1998, 203:435-450.

81. Wang $\mathrm{S}$, Jiang $\mathrm{Y}$, Huang $\mathrm{H}$, Yang Q: [Expression and correlation with metastasis of E-cadherin, $\mathrm{CD} 44 \mathrm{H}$, matrix metalloproteinase-3, nm $23 \mathrm{H} 1$ and VEGF in nasopharyngeal carcinoma.] Lin Chuang Er Bi Yan Hou Ke Za Zhi 2004, 18:470-472.

82. Evron E, Dooley WC, Umbricht CB, Rosenthal D, Sacchi N, Gabrielson E, Soito $A B$, Hung DT, Ljung B, Davidson NE, Sukumar S: Detection of breast cancer cells in ductal lavage fluid by methylation-specific PCR. Lancet 2001, 357:1335-1336.

83. Yang J, Mani SA, Donaher JL, Ramaswamy S, Itzykson RA, Come C, Savagner P, Gitelman I, Richardson A, Weinberg RA: Twist, a master regulator of morphogenesis, plays an essential role in tumor metastasis. Cell 2004, 117:927-939.

84. Howe LR, Watanabe O, Leonard J, Brown AM: Twist is up-regulated in response to Wnt1 and inhibits mouse mammary cell differentiation. Cancer Res 2003, 63:1906-1913.

85. Yang MH, Wu KJ: TWIST activation by hypoxia inducible factor-1 (HIF-1): implications in metastasis and development. Cell Cycle 2008, 7:2090-2096.

86. Yang L, Jiang Y, Wu SF, Zhou MY, Wu YL, Chen GQ: CCAAT/enhancer-binding protein alpha antagonizes transcriptional activity of hypoxia-inducible factor 1 alpha with direct protein-protein interaction. Carcinogenesis 2008, 29:291-298.

87. Wu Y, Evers BM, Zhou BP: Small C-terminal domain phosphatase enhances snail activity through dephosphorylation. J Biol Chem 2009, 284:640-648.

88. Zhou BP, Deng J, Xia W, Xu J, Li YM, Gunduz M, Hung MC: Dual regulation of Snail by GSK-3beta-mediated phosphorylation in control of epithelialmesenchymal transition. Nat Cell Biol 2004, 6:931-940.

89. de Herreros AG, Peiro S, Nassour M, Savagner P: Snail family regulation and epithelial mesenchymal transitions in breast cancer progression. J Mammary Gland Biol Neoplasia 2010, 15:135-147.

doi:10.1186/bcr3065

Cite this article as: Andrews $\mathrm{J}$, et al:: The role and function of cadherins in

the mammary gland. Breast Cancer Research 2012, 14:203. 